\title{
Letter to Editor: Previous research in operating room scheduling and staffing
}

\author{
Franklin Dexter • Liam O'Neill
}

Received: 3 May 2010 /Accepted: 5 May 2010/Published online: 14 May 2010

(C) Springer Science+Business Media, LLC 2010

Persson and Persson describe operating room scheduling wherein patients receive care within days [1]. The paper is similar to our work published in 2000 [2]. We speculate that the similarity arises from the authors' assumptions being reasonable and realistic, as were ours. The insensitivity of results to the "on line" bin packing algorithm was published the preceding year (1999) [3], as was the requirement from the practical requirement from the integer nature of the problem to use at least a four-week period [4]. Persson and Persson are modeling the efficiency of use of OR time and yet lack the advances made in the $>100$ papers using those techniques since publication of Strum et al.'s 1999 paper [5]. Our 2000 paper [2] combined the research published

F. Dexter $(\bowtie)$

Department of Anesthesia, University of Iowa,

200 Hawkins Drive,

Iowa City, IA 52242, USA

e-mail: Franklin-Dexter@UIowa.edu

L. O'Neill

University of North Texas, Health Sciences Center,

3500 Camp Bowie Blvd.,

Fort Worth, TX 76107, USA independently in 1999. The paper from 2000 has 31 citations so reasonably could have been found by literature review. The two papers from 1999, on which the 2000 paper was based, have 42 and 77 citations, respectively.

\section{References}

1. Persson MJ, Persson JA (2010) Analysing management policies for operating room planning using simulation. Health Care Manag Sci 13:182-191

2. Dexter F, Macario A, O’Neill L (2000) Scheduling surgical cases into overflow block time - computer simulation of the effects of scheduling strategies on operating room labor costs. Anesth Analg 90:980-986

3. Dexter F, Macario A, Traub RD, Hopwood M, Lubarsky DA (1999) An operating room scheduling strategy to maximize the use of operating room block time-Computer simulation of patient scheduling and survey of patients' preferences for surgical waiting time. Anesth Analg 89:7-20

4. Dexter F, Macario A, Qian F, Traub RD (1999) Forecasting surgical groups' total hours of elective cases for allocation of block timeApplication of time series analysis to operating room management. Anesthesiology 91:1501-1508

5. Strum DP, Vargas LG, May JH (1999) Surgical subspecialty block utilization and capacity planning. A minimal cost analysis model. Anesthesiology 90:1176-1185 